\title{
HUBUNGAN ANTARA BEBAN KERJA DENGAN KELELAHAN KERJA KARYAWAN LAUNDRY DI KELURAHAN WARUNGBOTO KECAMATAN UMBULHARJO KOTA YOGYAKARTA
}

\author{
Murleni Wati MZ, Widodo Haryono \\ Fakultas Kesehatan Masyarakat, Universitas Ahmad Dahlan, Yogyakarta
}

\begin{abstract}
Background: A problem which related with ergonomy factor commonly caused by conformity between the worker with occupation circles completely include occupation tools and the energy need or the amount of calori which used by the worker. Light in weight occupation which must be done by a worker will depend on changes indication appear and can be measured by measuring human part of body such as the rapid artery beat. The kind of measuring done for knowing how big the physical load accepted by the worker so that cause weariness.

This experiment as a purpose to know the relation between the occupation weariness of the laundry workers in Kelurahan Warungboto Kecamatan Umbulharjo Yogyakarta City.

Method: The kind of this experiment is observational analytic with study program Cross Sectional. The data interpretation done by measuring of artery beat on wrist (radical artery) to see the respondent occupation load and measuring weariness by Reaction timer tool.

Result: From the test result statistic, so respondent there are relation between occupation load with occupation weariness Laundry worker in Kelurahan Warungboto Kecamatan Umbulharjo Yogyakarta city statistically mean (Sig-2 tailed 0,0000 ). Ho which states is no relationship between load with occupation weariness of the laundry worker "rejected" Ha which states there is relationship between load with occupation weariness of the laundry worker "accepted".

Conclusion: There are relation that mean between occupation load with occupation weariness of the laundry worker in Kelurahan Warungboto Kecamatan Umbulharjo Yogyakarta city.
\end{abstract}

Keyword: Occupation load, Artery beat, Occupation weariness and Reaction timer.

\section{PENDAHULUAN}

Indonesia sebagai salah satu dari negara terbesar di Dunia, sangat berkepentingan terhadap masalah kesehatan dan keselamatan kerja. Direktorat Bina Kesehatan Kerja sebagai salah satu institusi dibawah Ditjen Bina Kesehatan Masyarakat - Depkes RI mempunyai tugas pokok melaksanakan penyiapan perumusan kebijakan teknis, standarisasi, bimbingan teknis, evaluasi dan penyusunan laporan dibidang kesehatan kerja. ${ }^{1}$ Permasalahan yang berkaitan dengan faktor ergonomi umumnya disebabkan oleh adanya ketidaksesuaian antara pekerja dan lingkungan kerja secara menyeluruh termasuk peralatan kerja. Faktor-faktor penyebab terjadinya kecelakaan, baik dari aspek penyakit akibat kerja maupun kecelakaan kerja dapat mengganggu daya kerja seorang buruh. Misalnya, penerangan yang kurang cukup intensitasnya biasanya akan melelahkan mata. Suara gaduh dan bising berpengaruh pula pada daya ingat, termasuk konsentrasi pikiran, akibatnya terjadi kelelahan psikologis. ${ }^{2}$

Kesehatan kerja merupakan aplikasi kesehatan masyarakat di dalam suatu tempat (perusahaan, pabrik, kantor dan sebagainya) dan menjadi pasien dalam kesehatan masyarakat adalah pekerja dan masyarakat sekitar perusahaan. ${ }^{3}$ Dari sudut pandang ergonomi, setiap beban kerja yang diterima oleh seseorang harus sesuai atau seimbang baik terhadap kemampuan fisik, kognitif maupun keterbatasan manusia 
menerima beban tersebut. ${ }^{4}$ Setiap pekerjaan apapun jenisnya apakah pekerjaan tersebut memerlukan kekuatan otot atau pemikiran adalah merupakan beban bagi yang melakukan pekerjaan tersebut. Akibat beban kerja yang terlalu berat atau kemampuan fisik yang lemah, dapat mengakibatkan seorang pekerja menderita gangguan atau penyakit akibat kerja. Semua sikap tubuh yang tidak alamiah dalam bekerja, misalnya sikap menjangkau barang yang melebihi jangkauan tangan harus dihindarkan. ${ }^{5}$ Gejala kelelahan banyak dialami oleh karyawan yang pekerjaanya bersifat monoton dan berulang-ulang. Kelelahan akibat kerja sering kali diartikan sebagai proses menurunnya effisiensi dan berkurangnya kekuatan atau ketahanan fisik tubuh untuk terus melanjutkan kegiatan yang harus dilakukan ${ }^{6}$.

Dalam penelitian ini dipilih pada pekerja Laundry karena pekerjaan ini dianggap banyak menggunakan tenaga fisik, sehingga sangat berkaitan dengan kelelahan kerja. Laundry adalah salah satu bagian instalasi yang memberi jasa untuk mencuci berbagai jenis kain, Fenomena yang terjadi tersebut sangat menarik untuk diteliti dan diketahui lebih dalam. Berdasarkan studi pendahuluan pada tanggal 5-6 Mei 2010 keluhan dari karyawan Laundry dapat dirinci sebagai berikut, (1) mesin cuci yang digunakan untuk mencuci pakaian/kain, sebagian Laundry proses pengambilan air dilakukan secara manual sehingga karyawan selalu merasa pegal pada tangan dan pinggang karena mengangkat air berulang-ulang kali, (2) saat mengoperasikan mesin cuci mereka harus berdiri, sehingga karyawan sering merasa kram pada kaki, (3) pakaian yang berwarna putih, kerah baju, jeans disikat sehingga saat menyikat mereka sering merasa pegal pada tangan dan punggung karena membungkuk, (4) saat mengangkat pakaian mereka mengaku sakit pada pinggang, (5) saat menjemur atau mengangin-anginkan pakaian/kain mereka mengakui pegal pada tengkuk, dan nyeri dipunggung karena berkali-kali menunduk dan mendongak, (6) saat menyetrika mereka merasa lelah karena lama berdiri sehingga pekerja merasa $\mathrm{kram} / \mathrm{kaku}$ dikaki menjadi canggung dalam bergerak, pegal pada bahu karena tangan berulang kali maju dan mundur, (7) merasa mengantuk dan sakit kepala apabila terlalu lama bekerja. Dari keluhan-keluhan diatas pada umumnya karyawan merasa pegal-pegal pada pinggang, punggung dan bahu, merasa kantuk, kram pada kaki dan nyeri di punggung.

Sehingga penulis mencoba untuk melakukan penelitian yang berkaitan dengan hal tersebut. Latar belakang tersebut akhirnya mendorong penulis untuk melakukan penelitian dengan judul "hubungan antara beban kerja dengan kelelahan kerja pada karyawan Laundry di Kelurahan Warungboto Kecamatan Umbulharjo Kota Yogyakarta".

\section{METODE PENELITIAN}

Jenis penelitian adalah observasional analitik dengan rancangan studi Cross sectional. Studi ini mempelajari prevalensi, distribusi, maupun hubungan penyakit dan paparan dengan cara mengamati status paparan dan penyakit pada suatu saat (point time). Teknik pengambilan sampel dalam penelitian ini menggunakan teknik total sampling (totality sampling) dimana pengambilan sampel ini secara keseluruhan dan memenuhi criteria inklusi dan eksklusi. Penelitian ini dilaksanakan bulan Juli 2010 di semua tempat laundry yang ada di kelurahan Warung Boto.

Instrument penelitian data primer dengan pengukuran denyut nadi, mengukur kelelahan karyawan menggunakan reaksi timer, serta untuk memberikan pengesahan terhadap hasil penelitian melalui wawancara. Wawancara dilakukan untuk mengetahui umur, jenis kelamin, dan pendidikan.

KES MAS Vol. 5, No. 3, September $2011: 162-232$ 


\section{HASIL PENELITIAN DAN PEMBAHASAN}

\section{A. Hasil Penelitian}

\section{1) Deskripsi Lokasi Penelitian}

Kelurahan Warungboto terletak di kecamatan Umbulharjo Kota Yogyakarta, luas wilayah Warungboto $0,83 \mathrm{Km}^{2}$ dengan jumlah penduduk 9506 jiwa. Di Kelurahan Warungboto terdapat 23 Laundry dengan 62 orang karyawan. Laundry yang paling banyak terdapat di pinggir jalan Glagah Sari dan Janturan, namun dijalan yang lainnya juga ada terdapat Laundry.

\section{2) Analisis Univariat}

\section{a) Umur Responden}

Tabel 1. Karakteristik Responden Menurut Umur di Kelurahan Warungboto Kecamatan Umbulharjo Kota Yogyakarta.

\begin{tabular}{cccccc}
\hline & $\mathrm{N}$ & Range & Minimum & Maximum & Mean (rerata) \\
\hline Umur & 30 & 27 & 18 & 45 & 29,73 \\
\hline
\end{tabular}

Dari 30 responden Tabel 1 di atas menunjukkan bahwa umur responden dari 30 sampel, umur minimum 18, umur maksimum 45 dengan rerata umur 29,73 dan selisih umur tinggi dan terendah 27.

\section{b) Pendidikan}

Tabel 2. Karakteristik Responden Menurut Pendidikan Terakhir di Kelurahan

Warungboto Kecamatan Umbulharjo Kota Yogyakarta.

\begin{tabular}{llcc}
\hline No & Pendidikan & Jumlah & Persentase (\%) \\
\hline 1 & D. 1 & 1 & 3.3 \\
\hline 2 & SD & 3 & 10.0 \\
\hline 3 & SMA & 7 & 23.3 \\
\hline 4 & SMK & 3 & 10.0 \\
\hline 5 & SMP & 16 & 53.3 \\
\hline & Jumlah & 30 & 100.0 \\
\hline
\end{tabular}

Tabel 2 di atas menunjukkan bahwa 30 Responden yang diteliti pendidikan terakhir yang paling banyak adalah SMP 16 (53\%) dan pendidikan terakhir yang paling sedikit adalah D.11(3,3\%).

c) Beban Kerja 
Tabel 3. Beban Kerja Responden di Kelurahan Warungboto Kecamatan Umbulharjo Kota Yogyakarta.

\begin{tabular}{lcc}
\hline Beban Kerja & Jumlah & Persentase (\%) \\
\hline $\begin{array}{l}\text { Beban kerja tidak normal (tidak normal dalam } \\
\text { kategori ringan) }\end{array}$ & 23 & 76.7 \\
\hline Beban kerja normal & 7 & 23.3 \\
\hline Jumlah & 30 & 100.0 \\
\hline
\end{tabular}

Tabel 3 di atas menunjukkan bahwa 30 Responden yang diteliti memiliki beban tidak normal dalam kategori ringan sebesar $23(76,7 \%)$, yang beban kerjanya tidak normal sebesar $7(23,3 \%)$.

\section{d) Kelelahan Kerja}

Tabel 4. Kelelahan Kerja Responden di Kelurahan Warungboto Kecamatan Umbulharjo Kota Yogyakarta.

\begin{tabular}{lcc}
\hline \multicolumn{1}{c}{ Kelelahan Kerja } & Jumlah & Persentase (\%) \\
\hline Lelah & 20 & 66.7 \\
\hline Tidak Lelah & 10 & 33.3 \\
\hline Jumlah & 30 & 100.0 \\
\hline
\end{tabular}

Tabel 4 di atas menunjukkan bahwa 30 Responden yang diteliti lelah kerjanya sebesar $20(66,7 \%)$, yang tidak lelah sebesar $10(33,3 \%)$.

\section{3) Analisis Bivariat}

Tabel 5. Hubungan Antara Beban Kerja Dengan Kelelahan Kerja Karyawan Laundry di Kelurahan Warungboto Kecamatan Umbulharjo Kota Yogyakarta tahun 2010.

\begin{tabular}{|c|c|c|c|c|c|c|}
\hline \multirow{2}{*}{\multicolumn{2}{|c|}{ Variabel }} & \multicolumn{2}{|c|}{ Kelelahan } & \multirow{2}{*}{$x^{2}$} & \multirow{2}{*}{ C $195 \%$} & \multirow{2}{*}{$\begin{array}{l}\text { Sig-2 } \\
\text { Tailed }\end{array}$} \\
\hline & & $\mathrm{D}^{+}$(lelah) & $\mathrm{D}^{-}$(tidak lelah) & & & \\
\hline \multirow{2}{*}{$\begin{array}{c}\text { Beban } \\
\text { Kerja }\end{array}$} & $\mathrm{E}^{+}(\neq$normal $)$ & 20 & 3 & \multirow[t]{2}{*}{14,557} & \multirow{2}{*}{$\begin{array}{l}2,699- \\
22,023\end{array}$} & \multirow[t]{2}{*}{0,000} \\
\hline & $\mathrm{E}^{-}$(normal) & 0 & 7 & & & \\
\hline
\end{tabular}

Pada tabel 5 di atas menunjukkan bahwa hasil uji statistik dari 30 sampel terdapat hubungan yang bermakna antara Beban Kerja dengan Kelelahan Kerja Karyawan Laundry di Kelurahan Warungboto Kecamatan Umbulharjo Kota Yogyakarta, hasil analisis bivariat adalah terdapat hubungan antara beban kerja dengan kelelahan kerja Karyawan Laundry di kelurahan Warungboto kecamatan Umbulharjo Kota Yogyakarta dan secara statistik bermakna (Sig-2 Tailed 0,000). 


\section{B. Pembahasan}

\section{1) Beban Kerja Responden}

Beban kerja merupakan target yang harus diselesaikan oleh pekerja dalam beberapa waktu. Nilai beban kerja responden diperoleh dari hasil pengukuran denyut nadi pada pergelangan tangan (arteri radialis) dengan tingkat beban kerja tidak normal dalam kategori ringan sebanyak $23(76,7 \%)$. Hal ini diakibatkan karena pengaruh fisik responden dan terkadang responden sebelum berangkat kerja mereka telah melakukan kerja fisik yang kuat dirumah. Beban tersebut dapat berupa beban fisik maupun mental ${ }^{4}$.

\section{2) Kelelahan Kerja Responden}

Kelelahan kerja merupakan menurunnya kapasitas kerja dan ketahanan kerja dengan ditandai oleh rasa letih, lesu, dan sensasi lelah. Pengukuran kelelahan kerja pada responden dilakukan dengan Reaction Timer, yang hasilnya menunjukkan bahwa tingkat kelelahan responden sebanyak 20 $(66,7 \%)$. Hal itu diakibatkan karena responden kurang memanfaatkan waktu istirahat untuk istirahat dan juga diikuti oleh kemampuan organ yang menurun sehingga menyebabkan tenaga kerja semakin mudah lelah. Namun, hal itu bisa diantisipasi dengan istirahat yang cukup dan bekerja secara ergonomis. Kelelahan kerja mudah ditiadakan dengan cara istirahat. Istirahat merupakan suatu usaha pemulihan yang dapat dilakukan dengan berhenti bekerja sejenak atau tidur dan dilakukan dalam kondisi diluar tekanan ${ }^{7}$.

\section{3) Hubungan Kelelahan dan Bebab Kerja}

Hasil pengukuran beban kerja berdasarkan denyut nadi dengan kelelahan kerja berdasarkan pengukuran Reaction Timer pada Karyawan Laundry di Kelurahan Warungboto Kecamatan Umbulharjo Kota Yogyakarta sebanyak 30 Responden, terdapat hasil yang bervariasi dari tingkat beban kerja normal sebanyak 7 orang $(23.3 \%)$, beban kerja kerja tidak normal dalam kategori ringan 23 orang $(76.7 \%)$ dan tingkat kelelahan kerja yang bervariasi dari tingkat lelah sebanyak 20 orang $(66.7 \%)$, tidak lelah sebanyak 10 orang $(33,3 \%)$. Hasil analisis bivariat adalah terdapat hubungan yang bermakna antara beban kerja dengan kelelahan kerja Karyawan Laundry di Kelurahan Warungboto Kecamatan Umbulharjo Kota Yogyakarta secara statistik bermakna (Sig-2 Tailed 0,000) sehingga Ho ditolak dan Ha diterima karena nilai Sig-2 Tailed $<0,05$.

Hal ini diakibatkan karena semakin besar tingkat beban kerja pada karyawan maka dapat meningkatkan resiko kelelahan kerja. Faktor lain juga memungkinkan untuk terjadinya kelelahan kerja pada responden antara lain disebabkan oleh akibat lingkungan fisik tempat kerja yang kurang mendukung/ tidak ergonomis, kebisingan, tingkat subyektif suhu ruangan yang panas, akibat aktivitas kerja fisik yang panjang dan tanggung jawab yang besar dalam pekerjaannya.

Hubungan beban kerja dengan kelelahan kerja dipengaruhi oleh kemampuan tiap-tiap pekerja yang berbeda walaupun pekerja bekerja ditempat yang sama dan dengan latar belakang pendidikan yang sama. Kemampuan seseorang yang lain meskipun pendidikan dan pengalamannya sama dan bekerja pada suatu pekerjaan yang sama, perbedaan ini disebabakan karena kapasitas orang tersebut berbeda ${ }^{8}$. Kelelahan akibat kerja seringkali diartikan sebagai proses menurunnya efisiensi, performans kerja dan berkurangnya 
kekuatan/ketahanan fisik tubuh untuk terus melanjutkan kegiatan yang harus dilakukan'.

Hasil penelitian ini ditemukan bahwa pekerja Laundry Kelurahan Warungboto Kecamatan Umbulhrjo Kota Yogyakarta selama ini belum pernah dilakukan pemeriksaan kesehatan termasuk penelitian kelelahan kerja dengan Reaction Timer. Dengan demikian dapat diasumsikan bahwa kurangnya informasi terutama tentang kesehatan kerja dan bekerja yang ergonomis agar berkurangnya terjadi kelelahan dan kecelakaan kerja. Secara keseluruhan kondisi lingkungan, monotoni pekerjaan, posisi kerja, tempat kerja, intensitas dan durasi kerja/mental, sikap kerja, usia, beban kerja, waktu kerja. Faktorfaktor penyebab kelelahan adalah lingkungan tidak ergonomis, psikologi, emosi, sakit, monoton, intensitas dan durasi kerja/mental, sikap kerja, usia, beban kerja, waktu kerja, status gizi, jenis kelamin, status kesehatan ${ }^{9}$.

Mengenal dan memahami berbagai aspek penyakit akibat kerja sebagai salah satu resiko akibat pekerjaan atau lingkungan kerja, merupakan langkah awal guna untuk meminimalisasikan akibat yang tidak dikehendaki. Maka dari itu upaya pengendalian kelelahan kerja akibat beban kerja dengan menerapkan cara kerja yang ergonomis dan melakukan pemeriksaan kesehatan secara berkala terhadap pekerja sangat penting guna untuk meningkatkan derajat kesehatan dan pekerja yang kesehatannya masih normal dapat untuk mencegah terjadinya gangguan kesehatan.

\section{SIMPULAN DAN SARAN}

\section{A. Simpulan}

Berdasarkan hasil analisis dan pembahasan pada penelitian ini bahwa terjadinya kelelahan kerja dan beban kerja yang tidak normal dalam kategori ringan pada responden. Maka dapat disimpulkan ada hubungan yang bermakna antara beban kerja dengan kelelahan kerja Karyawan Laundry di Kelurahan Warungboto Kecamatan Umbulharjo Kota Yogyakarta secara statistik bermakna (Sig-2 Tailed 0,000 ) sehingga Ho ditolak dan Ha diterima karena nilai Sig-2 Tailed $<0,05$.

\section{B. Saran}

Saran yang dapat diberikan terkait dengan hasil penelitian adalah:

1) Bagi Pengusaha

Pengusaha agar bisa menerapkan cara kerja yang ergonomis dan mengurangi beban kerja, melakukan rotasi kerja yang lebih sering dan jangan terlalu sering memberikan lembur terhadap karyawannya dan pencahayaan ditempat kerja harus cukup.

2) Bagi Karyawan

Karyawan agar membiasakan diri berolahraga ringan seperti menggerakgerakkan kepala, tangan dan kakinya di sela-sela pekerjaanya ataupun pada saat istirahat. 


\section{DAFTAR PUSTAKA}

1. Depkes RI, 2010, Kesehatan dan Keselamatan Kerja, Depkes RI, Jakarta.

2. Suardi, R., 2005, Sistem Manajemen Keselamatan dan Kesehatan Kerja, PPM, Jakarta.

3. Notoatmodjo, S., 1997, IImu Kesehatan Masyarakat, Rineka Cipta, Jakarta.

4. Tarwaka, 2004, Ergonomi untuk Keselamatan, Kesehatan Kerja dan Produktivitas, UNIBA PRESS, Surakarta.

5. Nugraheni, M. D., 2009, Hubungan antara Beban Kerja dengan Tingkat Kelelahan Kerja Pada Operator Unit Spining IV Ring Frame Shift BPT B PT. APAC INTI CORPORA, Skripsi, IImu Kesehatan Masyarakat Fakultas Ilmu Keolahraan Universitas Negeri Semarang.

6. Nurmianto, E., 1998, Ergonomi Konsep Dasar dan Aplikasinya, Guna Widya, Surabaya.

7. Suma'mur, 1967, Higene Perusahaan dan Kesehatan Kerja, PT. Toko Gunung Agung, Jakarta.

8. Notoatmodjo, S., 2003, Prinsip-Prinsip Dasar IImu Kesehatan Masyarakat, Rineka Cipta, Jakarta.

9. Wignjosoebroto, S., 2003, Ergonomi Studi Gerak dan Waktu Teknik Analisis untuk Peningkatan Produktivitas Kerja, Guna Widya, Surabaya. 